\title{
Commentary: Thinking back about our routine use of carbon dioxide
}

\author{
Hidefumi Nishida, MD, and Takeyoshi Ota, MD, $\mathrm{PhD}$
}

\author{
From the Section of Cardiac Surgery, Department of Surgery, The University of Chicago, Chicago, Ill. \\ Disclosures: Authors have nothing to disclose with regard to commercial support. \\ Received for publication April 24, 2019; accepted for publication April 25, 2019; available ahead of print Jun 12 \\ 2019. \\ Address for reprints: Takeyoshi Ota, MD, PhD, Section of Cardiac Surgery, Department of Surgery, The \\ University of Chicago, 5841 S Maryland Ave, MC5040, Chicago, IL 60637 (E-mail: tota@ bsd.uchicago.edu). \\ J Thorac Cardiovasc Surg 2020;159:969 \\ $0022-5223 / \$ 36.00$ \\ Copyright (c) 2019 by The American Association for Thoracic Surgery \\ https://doi.org/10.1016/j.jtcvs.2019.04.071
}

We congratulate Vandenberghe and colleagues ${ }^{1}$ on the in vitro study to assess carbon dioxide behaviors in a bench-top setting mimicking an operating field of cardiac surgery. This article provides direct visualization of carbon dioxide in the thorax model as well as optical and concentration level comparison of several gas diffusors.

Cerebral and cardiac complications including air embolism are always critical issues in cardiac surgery. As in any other medical field, significant efforts have been made to prevent/reduce postoperative complications in terms of surgical strategies and other managements in the field of cardiac surgery. As one of those strategies, it has been well implemented to use carbon dioxide insufflation in the surgical field to presumably reduce the incidence of air embolism. The exact efficacy of the use of carbon dioxide in cardiac surgery has been controversial. As the authors described, carbon dioxide theoretically has benefits over air in the biochemical standpoint. The bottom line would be it is at least harmless and brings several potential benefits. However, the behavior of carbon dioxide in the actual operating field (ie, open thorax) has not been well studied. ${ }^{2}$

In the present study, Vandenberghe and colleagues ${ }^{1}$ successfully visualized the current of carbon dioxide using a Charged Coupled Device camera and the Schlieren technique. They demonstrated that carbon dioxide behaviors varied depending on the diffusor types, gas delivery flow rate, hand motions, and use of suction in the field. They reported that the type of diffusor and the flow rate were especially important to maximize the gas concentration in the open thorax model. Although only a handful of relevant studies on this topic are available in the literature, some investigators such as Persson and colleagues ${ }^{4,5}$ also reported similar results in their studies. However, the most important contribution of this article ${ }^{1}$ is that they visualized carbon dioxide. It is "surgeon-friendly" enough to remind them what they are dealing with in their operating room/

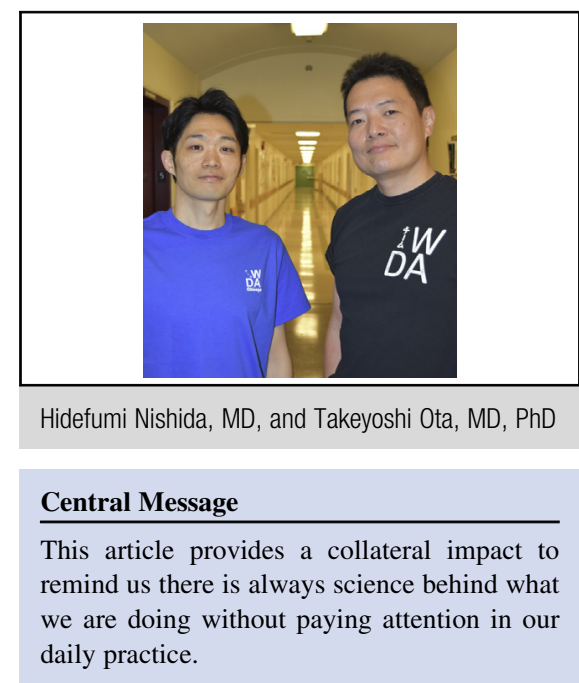

See Article page 958.

field. It is impressive that the videos demonstrated how the use of surgical instruments or hand motions, such as tying knots, affected carbon dioxide distribution in the field.

It is important to note that the efficacy or clinical benefits in the use of carbon dioxide is still unclear and debatable, and carbon dioxide behavior in this in vitro experiment might be different in the real operating field. Further studies are warranted. On the other hand, this article ${ }^{1}$ definitely gives us a new insight about the use of carbon dioxide and reminds us there is always science behind what we are using as a "voodoo" in our daily practice.

\section{References}

1. Vandenberghe S, Iseli D, Demertzis S. Direct visualization of carbon dioxide field flooding: optical and concentration level comparison of diffusor effectiveness. $J$ Thorac Cardiovasc Surg. 2020;159:958-68.

2. Sun Y, Ji B, Zhu X, Zheng Z. Efficacy of carbon dioxide insufflation for cerebra and cardiac protection during open heart surgery: a systematic review and metaanalysis. Artif Organs. 2013;37:439-46.

3. Chaudhuri K, Storey E, Lee GA, Bailey M, Chan J, Rosenfeldt FL, et al. Carbon dioxide insufflation in open-chamber cardiac surgery: a double-blind, randomized clinical trial of neurocognitive effects. J Thorac Cardiovasc Surg. 2012;144: 646-53.e1.

4. Persson M, Svenarud P, van der Linden J. What is the optimal device for carbon dioxide deairing of the cardiothoracic wound and how should it be positioned? J Cardiothorac Vasc Anesth. 2004;18:180-4.

5. Persson M, Van Der Linden J. De-airing of a cardiothoracic wound cavity model with carbon dioxide: theory and comparison of a gas diffuser with conventional tubes. J Cardiothorac Vasc Anesth. 2003;17:329-35. 